\title{
Recurrent acute pancreatitis secondary to a duodenal duplication cyst in an adult. A case report and literature review
}

\author{
Nikolaos S Salemis MD PhD¹, Christos Liatsos MD², Michail Kolios MD³, Stavros Gourgiotis MD ${ }^{1}$
}

NS Salemis, C Liatsos, M Kolios, S Gourgiotis. Recurrent acute pancreatitis secondary to a duodenal duplication cyst in an adult. A case report and literature review. Can J Gastroenterol 2009;23(11):749-752.

Duodenal duplication cysts are rare congenital abnormalities that are most commonly diagnosed in infancy and childhood. However, in rare cases, the lesion can remain asymptomatic until adulthood. An extremely rare case of a previously healthy adult patient with recurrent acute pancreatitis, who was diagnosed with a duodenal duplication cyst is presented. At laparotomy, a duplication cyst measuring $4.8 \mathrm{~cm}$ $\times 4 \mathrm{~cm} \times 4 \mathrm{~cm}$ was found adjacent to the ampulla of Vater. A partial cyst excision and marsupialization into the duodenal lumen was performed. The patient is healthy and asymptomatic four years after surgery. The present case illustrates the necessity of considering a duodenal duplication cyst in the differential diagnosis of recurrent acute pancreatitis in previously healthy adults.

Key Words: Congenital anomalies; Duodenal duplication cyst; Pancreatitis; Recurrent

astrointestinal duplication cysts are rare, benign, congen-

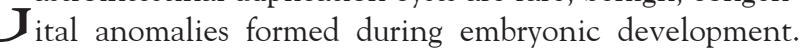
Although they may occur anywhere throughout the digestive tract - from mouth to anus $-75 \%$ of cases are located in the abdominal area (1). Abdominal duplications most commonly occur in the ileum $(2,3)$. In most cases, the disease is diagnosed during infancy or childhood (2), in which $60 \%$ of the patients are younger than two years of age at presentation (4). However, in rare cases, the duplication cyst may remain asymptomatic until adulthood (5). The present article describes an extremely rare case of a 64-year-old man with recurrent acute pancreatitis who was diagnosed with a duodenal duplication cyst. Diagnostic evaluation and surgical management are discussed, followed by a review of the literature.

\section{CASE PRESENTATION}

A 64-year-old man presented with an $8 \mathrm{~h}$ history of suddenonset, epigastric and upper abdominal pain associated with nausea and vomiting. The pain became progressively worse and radiated to his back. His medical history was unremarkable and he denied having any abdominal symptoms in the past. On admission, physical examination showed a moderately distressed patient with a temperature of $38^{\circ} \mathrm{C}$, a respiratory rate of 16 breaths/min, a blood pressure of 140/85 $\mathrm{mmHg}$ and a pulse rate of 85 beats $/ \mathrm{min}$. Abdominal examination revealed

\section{Récurrence de pancréatite aiguë secondaire à un kyste de la duplication duodénale chez un adulte. Rapport de cas et revue de la littérature}

La récurrence de pancréatite aiguë secondaire à un kyste de la duplication duodénale est une rare anomalie congénitale que l'on diagnostique plus souvent chez le nouveau-né et l'enfant. Toutefois, dans de rares cas, la lésion peut demeurer asymptomatique jusqu'à l'âge adulte. On présente ici le cas extrêmement rare d'un patient adulte auparavant en bonne santé, qui a présenté une récurrence de pancréatite aiguë et a reçu un diagnostic de kyste de la duplication duodénale. À la laparotomie, on a découvert un kyste de la duplication de $4,8 \mathrm{~cm} \times 4 \mathrm{~cm} \times 4 \mathrm{~cm}$ à proximité de l'ampoule de Vater. On a procédé à une excision partielle du kyste et à sa marsupialisation dans la lumière duodénale. Le patient est en bonne santé et ne présente aucun symptôme quatre ans après la chirurgie. Le présent cas illustre la nécessité d'envisager un kyste de la duplication duodénale lors du diagnostic différentiel de récurrence de pancréatite aiguë chez des adultes auparavant en bonne santé.

diffuse epigastric and upper abdominal tenderness. There was no abdominal wall rigidity or guarding, and bowel sounds were diminished. A hemogram revealed a white blood cell count of $6.88 \times 10^{9} / \mathrm{L}$ with $78 \%$ neutrophils, a hemoglobin level of $118 \mathrm{~g} / \mathrm{L}$ and hematocrit of $35.8 \%$. Biochemical investigations showed increased serum levels of amylase (1216 U/L; normal $25 \mathrm{U} / \mathrm{L}$ to $125 \mathrm{U} / \mathrm{L})$, urine amylase (20,490 U/L; normal $0 \mathrm{U} / \mathrm{L}$ to $400 \mathrm{U} / \mathrm{L})$, aspartate aminotransferase (33 U/L; normal $5 \mathrm{U} / \mathrm{L}$ to $40 \mathrm{U} / \mathrm{L}$ ), alanine aminotransferase (59 U/L; normal $5 \mathrm{U} / \mathrm{L}$ to $40 \mathrm{U} / \mathrm{L}$ ) and alkaline phosphatase (48U/L; normal $40 \mathrm{U} / \mathrm{L}$ to $140 \mathrm{U} / \mathrm{L})$. Total bilirubin, glucose, renal function tests and electrolytes were within the normal ranges. Abdominal ultrasonography revealed a normal liver, gallbladder and biliary duct system, but the pancreas was poorly demonstrated due to the presence of intraabdominal gases. The patient was treated conservatively with discontinuation of oral intake and administration of intravenous fluids and antibiotics. Contrast-enhanced computed tomography scans revealed a cystic lesion measuring $4.8 \mathrm{~cm} \times 4 \mathrm{~cm}$ in size, without nodular enhancement, in the second part of the duodenum (Figure 1). On magnetic resonance imaging (MRI), a thick-walled $(1 \mathrm{~cm})$ cystic mass was demonstrated on T1 and T2 images, indicative of a duodenal cystic mass (Figures 2 and 3). Upper gastrointestinal endoscopy revealed a polypoid lesion protruding into the lumen of the second part of the duodenum in the papilla of Vater (Figure 4). Endoscopic ultrasonography

${ }^{1}$ 2nd Department of Surgery; ${ }^{2}$ Department of Gastroenterology; ${ }^{3}$ Department of Radiology, Army General Hospital, Athens, Greece

Correspondence: Dr Nikolaos S Salemis, 19 Taxiarhon Street, 19014 Kapandriti, Athens, Greece. Telephone 30-22950-23559,

fax 30-210-6140808, e-mail nikos_salemis@hotmail.com

Received for publication February 4, 2009. Accepted March 12, 2009 


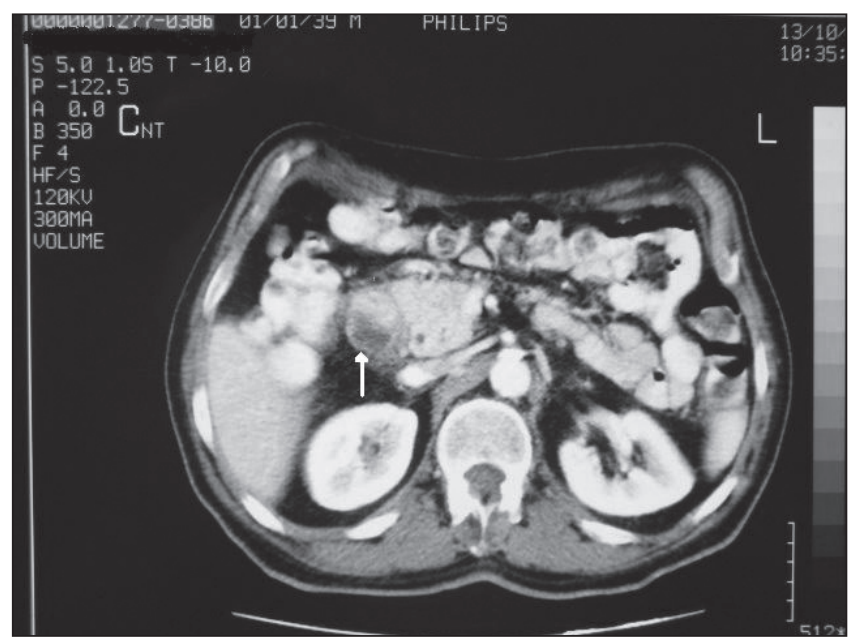

Figure 1) Contrast-enhanced computed tomography scans of the abdomen demonstrating a cystic lesion, without nodular enhancement in the second part of the duodenum (arrow)

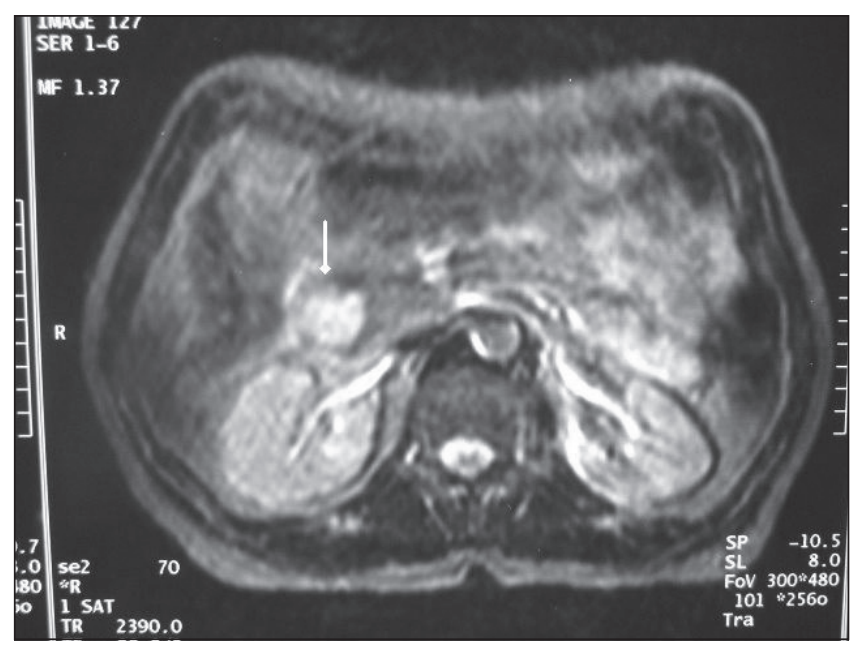

Figure 2) T2-weighted magnetic resonance image demonstrating a focal lesion, with increased signal intensity in the second part of the duodenum (arrow)

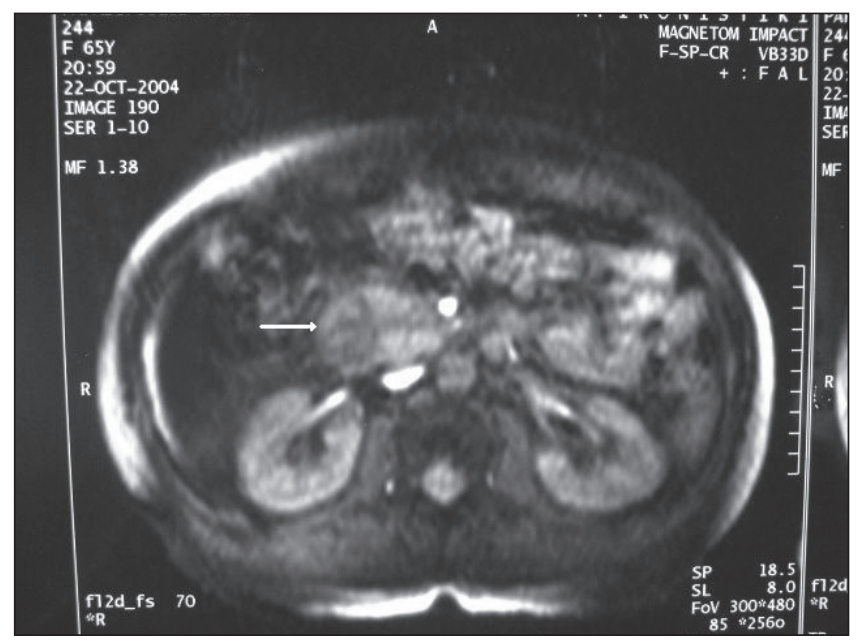

Figure 3) T1-weighted magnetic resonance image after administration of gadolinium-diethylene triamine pentaacetic acid, demonstrating a thick-walled focal lesion with low signal intensity in the second part of the duodenum (arrow)

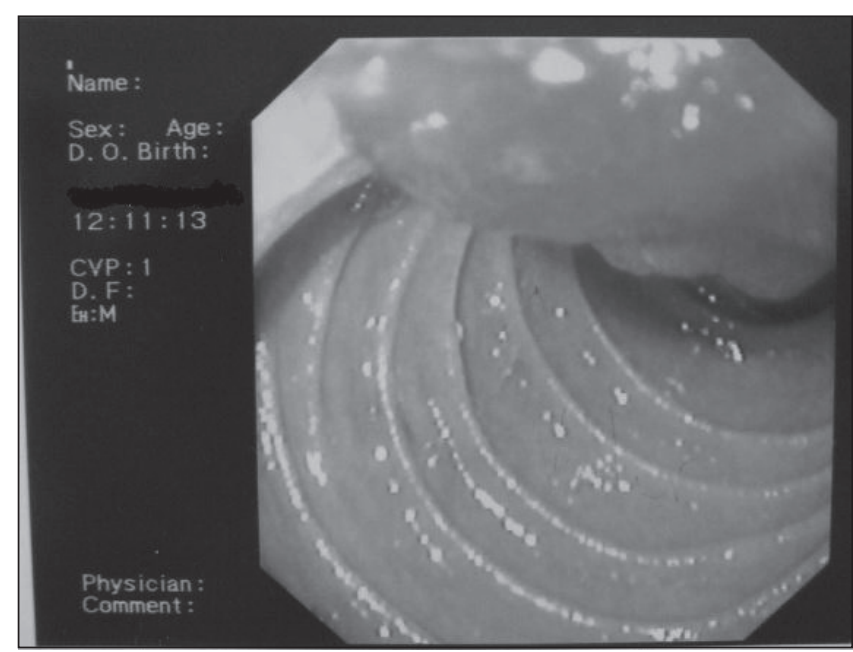

Figure 4) Upper gastrointestinal endoscopy demonstrating a polypoid lesion protruding into the lumen of the second part of the duodenum in the papilla of Vater

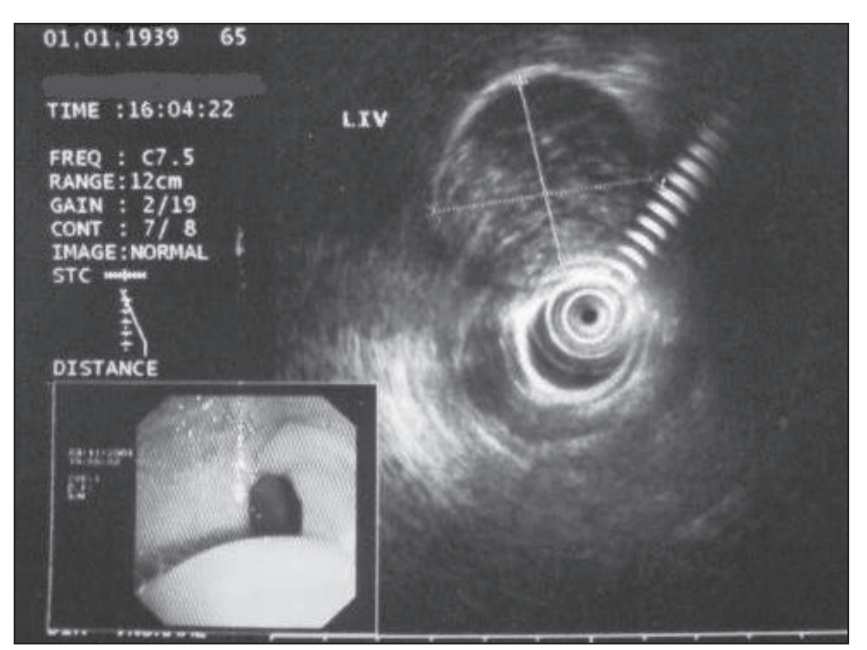

Figure 5) Endoscopic ultrasonography demonstrating the cystic duodenal lesion containing debris

confirmed the above findings (Figure 5). During the next 20 days of hospital stay, the patient developed two typical episodes of acute pancreatitis that were clinically and laboratory confirmed. At exploratory laparotomy, performed after complete resolution of the last episode of acute pancreatitis, a large duplication cyst measuring $4.8 \mathrm{~cm} \times 4 \mathrm{~cm} \times 4 \mathrm{~cm}$ was found in the second part of the duodenum in the papilla of Vater. The cyst was opened and its anterior wall was resected, whereas its posterior surface was marsupialized into the duodenum. Intraoperative biopsies were obtained and thorough investigation of the remnant cyst wall was performed to exclude any abnormalities or ectopic tissues. Histopathological examination of the excised cyst segment revealed normal duodenal mucosa on both sides of the specimen separated by a smooth muscle wall, indicative of a duodenal duplication cyst. There was no evidence of malignancy or dysplasia. The postoperative course was uneventful and the patient was discharged home eight days later. He remains healthy and asymptomatic four years after surgery. 


\section{DISCUSSION}

Duplication cysts can be either tubular or spherical, and their size varies widely. They are most commonly encountered in or adjacent to the gastrointestinal wall, composed of at least one smooth muscle layer and are lined by a mucosal membrane not necessarily corresponding to the mucosa at the level of attachment (1). They are most frequently located at the mesenteric border of the digestive tract sharing a common smooth muscular wall and blood supply with the adjacent bowel (2), whereas $25 \%$ to $35 \%$ of the cysts contain ectopic mucosa, most commonly of gastric origin $(1,4)$. Clinical signs are vague and related to the location and size of the cysts (5). Abdominal duplications may present with abdominal pain and distension, and more rarely with manifestations of intestinal obstruction, intussusception or bleeding, especially when ectopic gastric tissue is present $(1,5)$.

Duodenal duplication cysts (DDCs) are rare, accounting for only $5 \%$ to $7 \%$ of all gastrointestinal duplications $(2,6)$, and most commonly encountered in the first and second parts of the duodenum $(6,7)$. In a literature review of Japanese patients, Yamauchi et al (7) found 49 cases of DDCs. There was a female predominance, but the distribution among children and adults was almost equal. Pediatric patients most commonly presented with vomiting, abdominal mass and fever, whereas the most common findings in adults were upper abdominal pain and gastrointestinal bleeding, mainly due to the presence of ectopic gastric mucosa (7). Rare manifestations of DDCs include pancreatitis (5,8-13), biliary obstruction $(11,13-15)$ intussusception $(15,16)$ and infection (7). Regarding pancreatitis, occlusion of the pancreatic ductal system by the distended duplication cyst, which occasionally may contain secretions, sludge or stones, seems to be the major causative factor (13).

In a review of the English literature, Kawahara et al (8) found 25 cases of acute pancreatitis caused by duplication cysts both in children and adolescents. The disease occurred more commonly in females, in whom the most common presenting symptoms were abdominal pain, nausea and vomiting. The age of the patients ranged from nine months to 16 years. In $60 \%$ of the cases, the duplication cysts were in continuity with the duodenum and were located close to the ampulla of Vater, whereas communication with the pancreaticobiliary tract was documented in $56 \%$ of the cases and a synchronous pancreatic peudocyst was detected in $32 \%$ of the patients.

Computed tomography of the abdomen and ultrasonography have been more frequently used in the diagnosis of DDCs (8), along with upper gastrointestinal series, endoscopic ultrasound, endoscopic retrograde cholangiopancreatography, MRI and multidetector computed tomography in combination

\section{REFERENCES}

1. Naik-Mathuria B, Olutoye OO. Foregut abnormalities. Surg Clin North Am 2006;86:261-84.

2. Macpherson RI. Gastrointestinal tract duplications: Clinical, pathologic, etiologic, and radiologic considerations. Radiographics 1993;13:1063-80.

3. Stringer MD, Spitz L, Abel R, et al. Management of alimentary tract duplication in children. Br J Surg 1995;82:74-8.

4. Ildstad ST, Tollerud DJ, Weiss RG, Ryan DP, McGowan MA, Martin LW. Duplications of the alimentary tract. Clinical characteristics, preferred treatment, and associated malformations. Ann Surg 1988;208:184-9.

5. Niehues R, Dietl KH, Bettendorf O, Domschke W, Pohle T. with multiplanar reformation (16). In the present case, MRI images adequately detected the thick-walled duodenal cystic mass, providing useful information for the planning of the surgical intervention. The use of MRI in the diagnostic work up of DDCs has been rarely reported (17). Endoscopic retrograde cholangiopancreatography was not feasible because the large mass was located adjacent to the major papilla.

Differential diagnosis of DDCs include cystic dystrophy of the duodenal wall, type III choledochoceles, pancreatic cysts and any other cystic mass in the pancreaticoduodenal region (10). Discrimination from choledochocele is very difficult and the principal distinguishing features are the histological characteristics (18). Special attention is needed when differentiating DDCs from cystic pancreatic tumours because a few cases of increased intracystic levels of amylase, carcinoembryonic antigen and carbohydrate antigen $19-9$ have been reported $(7,19)$. However, the clinical significance of increased levels of tumour markers within DDCs is unknown (19).

Surgical intervention has traditionally been the treatment of choice for DDCs (11). The two main types of surgical intervention are complete resection of the cyst and partial resection combined with drainage procedures (8). Complete resection is the preferred treatment. In many cases, however, due to the close proximity of the cyst to the major papilla, complete resection may not be safe because there is a possibility of damaging the biliary and pancreatic ducts. Alternatively, partial resection, marsupialization, mucosal stripping, and internal or Roux-en-Y drainage have been reported $(1,9)$.

Endoscopic management of DDCs has been described as a safe alternative to surgical intervention (12-14,20). In a retrospective case series, Antaki et al (13) reviewed eight patients ranging in age from eight to 72 years who were treated endoscopically, and found that all patients remained asymptomatic at a median follow-up of 7.3 years. They suggested that endoscopic treatment is safe and effective, and may be considered the preferred therapeutic approach for DDCs. However, this study was limited by a small number of patients.

Although DDCs are benign clinical entities, a few cases with malignant tumour development have been reported (21-23). This malignant potential necessitates the need for a long-term follow-up in patients who have undergone partial removal of a DDC (8).

\section{CONCLUSION}

We describe a very rare case of an adult patient who was diagnosed with a DDC. Although rare, this clinical entity should be kept in mind in the differential diagnosis of recurrent acute pancreatitis in previously healthy adults.

Duodenal duplication cyst mimicking pancreatic cyst in a patient with pancreatitis. Gastrointest Endosc 2005;62:190-2.

6. Russo MA, Redel CA. Anatomy, histology, embryology, and developmental anomalies of the stomach and duodeum. In: Feldman M, Friedman LS, Brandt LJ, eds. Sleisenger \& Fordtran's Gastrointestinal and Liver Disease, 8th edn. Philadelphia: Saunders Elsevier, 2006:981-98.

7. Yamauchi Y, Hoshino S, Yamashita Y, Funamoto S, Ishida K, Shirakusa T. Successful resection of an infected duodenal duplication cyst after percutaneous cyst drainage: Report of a case. Surg Today 2005;35:586-9.

8. Kawahara H, Takahashi T, Okada A. Characteristics of duodenal 
duplications causing pancreatitis in children and adolescents: A case report and review of the literature. J Pediatr Gastroenterol Nutr 2002;35:372-6.

9. Keller MS, Weber TR, Sotelo-Avila C, Brink DS, Luisiri A. Duodenal duplication cysts: A rare cause of acute pancreatitis in children. Surgery 2001;130:112-5.

10. Guarise A, Faccioli N, Ferrari M, Romano L, Parisi A, Falconi M. Duodenal duplication cyst causing severe pancreatitis: Imaging findings and pathological correlation. World J Gastroenterol 2006;12:1630-3.

11. Jo YC, Joo KR, Kim DH, et al. Duodenal duplicated cyst manifested by acute pancreatitis and obstructive jaundice in an elderly man. J Korean Med Sci 2004;19:604-7.

12. Rockx MA, McAlister VC. Endoscopic fenestration of a duodenal duplication cyst to resolve recurrent pancreatitis. JOP 2007;8:795-8.

13. Antaki F, Tringali A, Deprez P, et al. A case series of symptomatic intraluminal duodenal duplication cysts: Presentation, endoscopic therapy, and long-term outcome (with video). Gastrointest Endosc 2008;67:163-8.

14. Sezgin O, Altiparmak E, Yilmaz U, Saritas U, Sahin B. Endoscopic management of a duodenal duplication cyst associated with biliary obstruction in an adult. J Clin Gastroenterol 2001;32:353-5.

15. Zamir G, Gross E, Shmushkevich A, Bar-Ziv J, Durst AL, Jurim O. Duodenal duplication cyst manifested by duodeno-jejunal intussusception and hyperbilirubinemia. J Pediatr Surg 1999;34:1297-9.

16. Morley NP, Pyrros AT, Yaghmai V, Miller FH, Nikolaidis P. Biliary dilatation and duodenal intussusception secondary to enteric duplication cyst. MDCT diagnosis. Emerg Radiol 2009;16:243-5.

17. Rotondo A, Scialpi M, Pellegrino G, et al. Duodenal duplication cyst: MR imaging appearance. Eur Radiol 1999;9:890-3.

18. Tanaka S, Goubaru M, Ohnishi A, et al. Duodenal duplication cyst of the ampulla of Vater. Intern Med 2007;46:1979-82.

19. Shah KJ, Malleo G, Low J, Skordilis K, Makin AJ, Siriwardena AK. Duodenal duplication cyst with profound elevation of intracystic carbohydrate antigen (CA 19-9) and carcinoembryonic antigen (CEA): A rare but important differential in the diagnosis of cystic tumours of the pancreas. JOP 2006;7:200-4.

20. Vandenbroucke F, Dagenais M, Létourneau R, Lapointe R, Roy A. Endoscopic treatment of a duodenal duplication cyst. Endoscopy 2005;37:601.

21. Falk GL, Young CJ, Parer J. Adenocarcinoma arising in a duodenal duplication cyst: A case report. Aust N Z J Surg 1991;61:551-3.

22. Hata H, Hiraoka N, Ojima H, Shimada K, Kosuge T, Shimoda T. Carcinoid tumor arising in a duplication cyst of the duodenum. Pathol Int 2006;56:272-8.

23. Inoue M, Nishimura O, Andachi H, Koga S. Early cancer of duodenal duplication. A case report. Gastroenterol Jpn $1979 ; 14: 233-7$. 


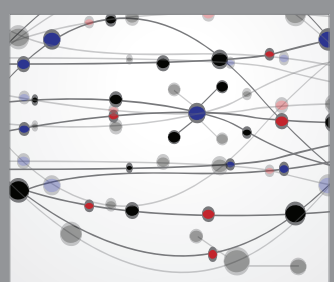

The Scientific World Journal
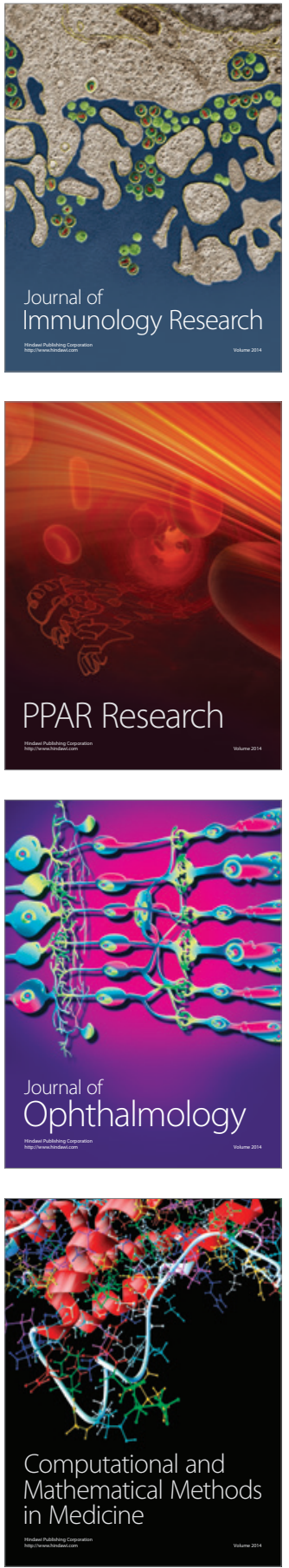

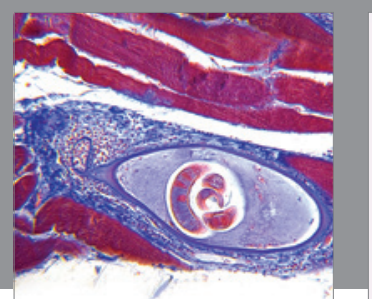

Gastroenterology Research and Practice

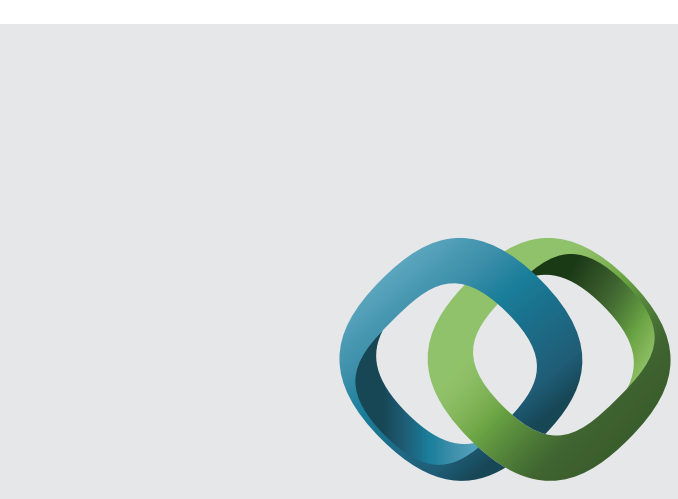

\section{Hindawi}

Submit your manuscripts at

http://www.hindawi.com
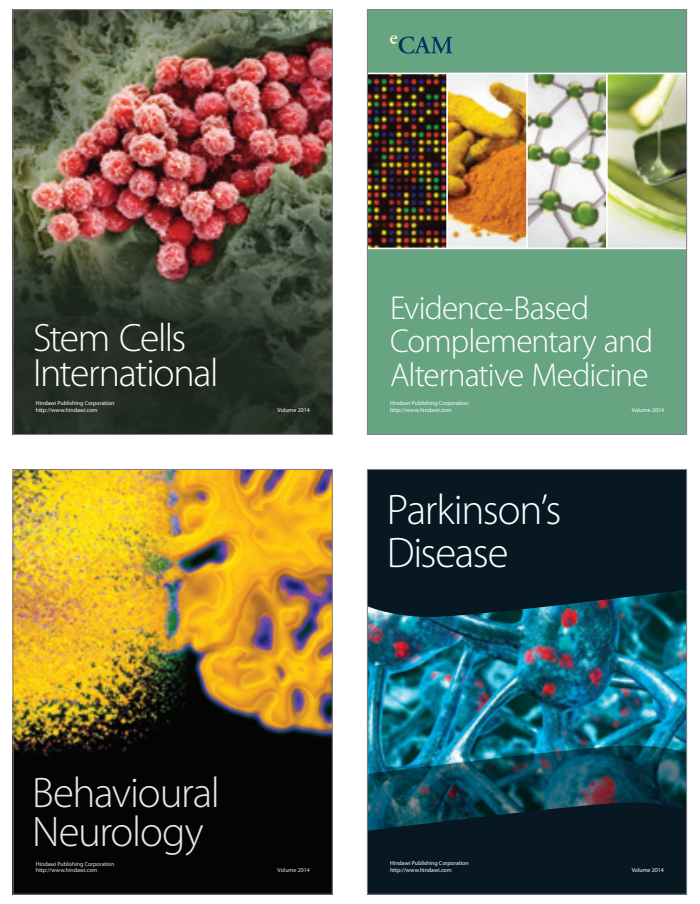
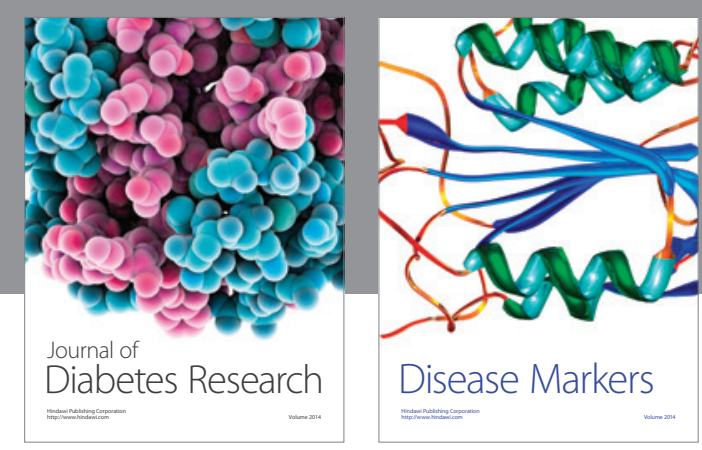

Disease Markers
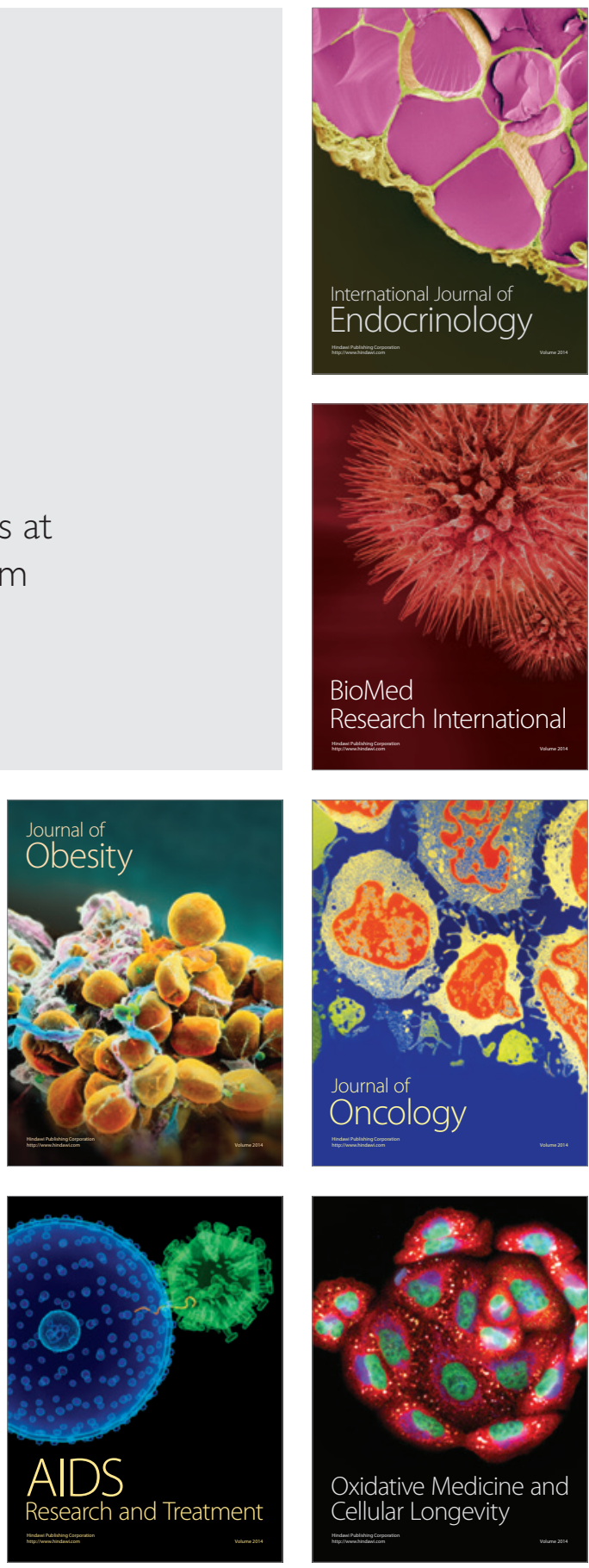